\title{
Path Analysis of Intellectual Property Achievement Transformation in Colleges and Universities
}

\author{
Rui Shang \\ Heilongjiang Bayi Agricultural University, Daqing, China \\ byndkjccgk@126.com
}

\begin{abstract}
Intellectual property is one of the important references for enhancing the national scientific and technological strength, comprehensive national strength and international competitiveness, the transformation and protection of their achievements are deeply valued. Since the new period, with the continuous development and progress of science and technology in China, the protection of intellectual property and the transformation of achievements are facing new situations and challenges. On the one hand, as an important component of intellectual property, the achievements transformation in colleges and universities are increasingly remarkable. On the other hand, as the decisive role of the market becomes increasingly prominent, the system and policy constraints of the original intellectual property achievements transformation become increasingly prominent. This study will clarify the possible path of the transformation of intellectual property achievements in Chinese colleges and universities in the future through the background, current situation, main problems and analysis, countermeasures and suggestions of intellectual property achievements transformation in colleges and universities in China.
\end{abstract}

Keywords: Intellectual property in colleges and universities, Achievement transformation path, Government, Enterprise

\section{Background and status}

Since the new century began, the Communist Party of China and the People's Republic of China have paid more attention to scientific and technological innovation. The 19th National Congress of the Party clearly regards innovation-driven strategy as one of the major strategies to realize a well-off society in an all-round way and the great rejuvenation of the Chinese nation the Chinese dream. The transformation of intellectual property achievements in colleges and universities is undoubtedly an important symbol of China's scientific and technological innovation and the improvement of its comprehensive national strength.

Since the implementation of National Intellectual Property Strategy Compendium, the creation, application, protection and management of intellectual property in domestic universities have been effectively promoted. Universities have constantly improved their intellectual property management system and actively carried out the transformation and application of intellectual property. In recent years, relevant departments of the state and the government have successively issued documents such as "Decision on Amending the Law of the People's Republic of China on Promoting the Transformation of Scientific and

Article history:

Received (March 21, 2020), Review Result (April 25, 2020), Accepted (June 2, 2020) 
Technological Achievements" (Decree No.32 of the President of the People's Republic of China) and "Several Opinions of the Ministry of Education and the Ministry of Science and Technology on Strengthening the Transfer and Transformation of Scientific and Technological Achievements in Colleges and Universities" [1] (No.3 [2016] of the Ministry of Education). At present, most colleges and universities in our country have established fulltime and part-time intellectual property management agencies, and most of them have established intellectual property ownership and benefit distribution systems. This has effectively promoted the transformation of intellectual property achievements in colleges and universities. As a result, many intellectual property achievements in colleges and universities have entered the market and played a positive role in the development of industries and trades.

However, with the continuous development and progress of science and technology, the bottleneck of science and technology system is increasingly obvious. Although the quantity and quality of patents owned by universities in China have improved significantly, the direct promotion of a large number of patents to the market economy is still limited. At present, the transformation of intellectual property in domestic universities faces a series of problems and development obstacles such as low innovation quality, insufficient self-understanding, weak financial support, weak market awareness, imperfect system and mechanism, etc.

\section{Problem}

At present, the transformation of intellectual property achievements in many colleges and universities is not optimistic, and there are various problems, mainly including the following aspects:

First, the quality of the achievement transformation process. A large number of intellectual property achievements have no clear application objects and conditions for industrialization before research, development and production. In addition, scientific and technological projects have their own defects, such as imperfect research programs or lack of funds, which makes it difficult to carry out medium-term pilot application and later transformation.

Second, the transformation of achievements has not been combined with market demand. The achievements of intellectual property in colleges and universities are derailed from local industries and trades, and the feasibility of later transformation is poor. Local colleges and universities are far away from the principle of market orientation. Most enterprises lack trust in the scientific research ability of local colleges and universities, and many intellectual property achievements are immature and lack social practicability.

Third, the management system of intellectual property in Colleges and universities. The relevant systems of intellectual property management in colleges and universities are not perfect and lack of systematic management mechanism, which leads to the disconnection of intellectual property achievement management. Some local colleges and universities are prone to plagiarism of scientific research results due to their weak strength in running schools and weak awareness of intellectual property. In addition, in some weak and poorly managed universities, the salary of supporting faculty is unreasonable, which leads to teachers' passive resignation, the interruption of scientific research projects, and even the outflow of patent achievements.

Fourth, the concept of transformation of achievements by teachers and scientific and technological personnel is backward. Most scientific and technological personnel lack the sense of competition in the transformation of achievements and seldom consider the transformation of intellectual property achievements or industrialization. Under the influence 
of professional title-oriented thinking, there is a lack of awareness of social services and industrialization of intellectual property achievements, and the motivation for subsequent patent transformation is insufficient.

Fifth, there is a deviation in the implementation effect of the local government's release, management and service work. On the one hand, the state's "intervention power" has been delegated rapidly, making it difficult to fully grasp the actual situation of the transformation of achievements. On the other hand, there are many administrative interventions by local governments, resulting in problems such as disorder of technology market order [2].

\section{Cause analysis}

In view of the above problems, we analyze the main reasons as follows:

(1) Analysis of government problems: Although the state's "intervention power" has been decentralized rapidly, it is difficult to fully grasp the specific situation of achievements transformation, especially in Colleges and universities. "Three decentralization" has promoted the enthusiasm of the transformation of University achievements, and the speed and effectiveness of the transformation have been constantly improved. However, too fast decentralization of "intervention power" also leads to unclear understanding of the status quo of invention patents, evaluation of transfer and transformation, effective integration of advantageous resources and improper layout [3]. In addition, preferential policies of local governments have been issued continuously, and various government-run platforms for the transformation of scientific and technological achievements have emerged continuously. Strong government intervention has partially disturbed the market attribute of the transformation of scientific and technological achievements.

(2) Analysis of colleges' own problems: First of all, the scientific and technological achievements in colleges and universities have not yet been managed in the whole process, resulting in improper disposal of the front-end links of scientific and technological achievements and loss of state-owned assets in the back-end links. Secondly, colleges and universities also ignore the whole process transformation of scientific and technological achievements. Colleges and universities should choose the most suitable transformation stage and mode based on technical characteristics, market demand and other factors. Many local colleges and universities lack in-depth cooperation and communication with enterprises, and often look for market demand only at the final stage of research and development work. This must create an embarrassing situation in which technological achievements look for the market instead of developing technologies according to market demand. Finally, it is difficult to judge the expected value of the preliminary research work, which is also an important reason why enterprises are not interested in the preliminary research and development work in colleges and universities. The maintenance time of local university patents is generally short, which will greatly affect the market competitiveness of local university patents and the effective transformation of intellectual property achievements.

(3) Analysis of teachers and researchers' own problems: The problem of teachers and scientific researchers is largely due to the problems of scientific and technological publicity, public opinion guidance and system guarantee in colleges and universities. At present, many colleges and universities lack of incentive mechanism and system guarantee, which leads to the lack of understanding of the importance of achievements transformation and the lack of prospective understanding of the development prospect of the integration of production, learning and research. Colleges and universities must establish an evaluation system that 
reasonably links intellectual property authorization and transformation with performance appraisal and professional title promotion, not only to encourage everyone to submit patent applications, but also to improve the enthusiasm of transformation [4].

(4) Analysis of the problems of small and medium-sized enterprises in science and technology: China's small and medium-sized science and technology enterprises have developed rapidly, but they still face some difficulties in the process of development, thus restricting the healthy development of science and technology enterprises. First, the ability to obtain and apply policy information is weak. Most of the small and medium-sized scientific and technological enterprises have not set up special policy research institutions, and the policy grasp is relatively backward, and lack of in-depth research and analysis. The second is the shortage of scientific and technological talents and achievements in enterprises. The technology of small and medium-sized science and technology enterprises mainly comes from institutions of higher learning and large scientific research institutes. These talents are difficult to retain and have great mobility. Some enterprises attach importance to short-term effects and are not very active in talent development and training. Third, some enterprises do not have strong awareness and ability to safeguard their own rights, do not attach importance to the protection of intellectual property, and the agreement on the ownership of intellectual property is unclear.

\section{Countermeasures and suggestions}

In view of the above problems and the analysis of existing problems, we believe that we should seek common channels for integration from the government, universities, enterprises, teachers and inventors at the same time in order to overcome the main obstacles to the transformation of scientific and technological achievements in universities:

\subsection{On the part of the government}

(1) The government's evaluation of the transformation of scientific and technological achievements in colleges and universities should not only prevent colleges and universities from paying too much attention to "star patents" in order to increase turnover, but also prevent deliberately lowering prices in order to increase turnover.

(2) Avoid the influence of excessive administrative intervention on the choice of achievement transformation. Colleges and universities must be guided to abide by the laws of the market. The transfer of patents should match the characteristics of the technology supply side and the transformation carrier, and the acceptance method should be selected under the legal framework and market logic.

(3) On the basis of clarifying the ownership relationship, the government should strengthen the intervention right system. Increase the intellectual property funds of scientific research projects in Colleges and universities, and pay more attention to the intellectual property investment in Colleges and universities, such as the establishment of national intellectual property maintenance and rescue fund. To improve the enthusiasm of transformation, local governments need to further clarify policies and measures, strengthen the protection of intellectual property, and create a good environment for the use of intellectual property. 


\subsection{On the joint mechanism of universities and enterprises}

Cultivating talents, developing science and technology and serving the society are three recognized functions of colleges and universities. From these functions, we can sum up the measures and ways for universities and enterprises to enhance cooperation in production, learning and research and enhance linkage mechanism:

(1) The transformation of scientific and technological achievements in colleges and universities should give priority to small and medium-sized enterprises and derivative enterprises.

(2) The whole process management of scientific and technological achievements: strictly implement the duty invention reporting system, and speed up the construction of knowledge management and intellectual property management information system in colleges and universities.

(3) Whole process transformation of scientific and technological achievements: considering factors such as technical characteristics and market environment, enterprises are encouraged to participate in the best stage of transformation of scientific and technological achievements flexibly, which not only improves their technological absorption capacity, but also reduces transaction costs.

(4) Top-level design and institutional mechanism. Issue a series of documents to promote the transformation of scientific and technological achievements, improve the transformation process of scientific and technological achievements, clarify the proportion of rewards for income distribution, build a regional platform for industry-university-research innovation services, and set up branches for technology transfer. With reference to the advanced experience of Zhejiang University, Shanghai Jiao Tong University, Jiangsu University and other universities in China, try a new mode of intellectual property operation, establish a national intellectual property analysis and evaluation center, and set up an intellectual property trading center to provide professional services for intellectual property trading.

(5) To establish a mode of transformation of intellectual property, first, the company holds shares and rewards them according to their shares. The second is the reward of intellectual property plus team commitment. Third, by dividing intellectual property in advance, the team contributed with monetary capital. The fourth is the way of expecting rights and interests plus self-employment.

(6) Platform construction and scientific and technological publicity. Innovation is the soul of small and medium-sized scientific and technological enterprises. Without innovation, enterprises will lose their motivation for development. Therefore, small and medium-sized science and technology enterprises must pay special attention to the protection and maintenance of intellectual property. On the one hand, colleges and universities can use platform clusters to guide enterprises to establish awareness of intellectual property, strengthen the declaration and protection of intellectual property, and provide policy services for enterprises. As for that protection of intellectual property right of enterprises, In addition to enhancing the self-protection awareness and ability of enterprises, Colleges and universities can also lead or participate in the construction of intellectual property information service platforms according to their actual conditions, set up intellectual property expert databases, participate in the construction of intellectual property research institutes, intellectual property protection associations and intellectual property protection centers in the province, and provide professional support for intellectual property value evaluation and 
dispute resolution. On the other hand, colleges and universities should actively carry out the activities of intellectual property science popularization, guide the whole society to establish the awareness of respecting and protecting intellectual property, bring intellectual property into the teaching curriculum, let the public form the habit of respecting innovation and actively safeguarding rights, and let intellectual property become conscious actions [5].

\subsection{For teachers and inventors}

(1) Inventors should clearly understand the commercial prospect and implementation path of patent application. Inventors should consider applying for patents in depth and invest human and financial resources to cooperate with the transfer and transformation. At the same time, as the first person responsible for the disclosure of service invention, colleges and universities must strictly implement the service invention report system, regularly carry out scientific research information management training for their own teaching staff, master / doctoral students, postdoctoral, etc., and take reasonable and necessary punishment measures for those who violate the service invention disclosure regulations.

(2) Clarify the value orientation of patent application and transfer and transformation. Teachers apply for patents because of promotion of professional titles and lack concern for subsequent patent transformation. Local colleges and universities should vigorously cultivate a scientific research atmosphere that promotes the combination of production and study and the promotion and transformation of achievements, and promote the construction of local university science parks and the industrialization of achievements. By strengthening the organic combination with enterprises and integrating into the national and local innovation systems, multi-party cooperation and win-win results can be realized. Local colleges and universities should strengthen the construction of innovative culture to form a good innovative environment and a harmonious innovative atmosphere. Leaders and managers in charge of intellectual property in colleges and universities should also fully realize the importance of improving the transformation of intellectual property in local colleges and universities. Therefore, only by carrying forward the main theme of innovation and entrepreneurship and advocating the cultural concept of intellectual property achievements transformation can teachers and students in local colleges and universities create a good environment for the transformation of intellectual property achievements in local colleges and universities [6].

\subsection{On the internal system and mechanism of colleges and Universities}

(1) Strengthen system design. Intellectual property system is the property system arrangement of market economy, In line with General Secretary Xi Jinping's point that "strengthening the protection of intellectual property is the most important content to improve the property rights protection system and the greatest incentive to improve China's economic competitiveness", Colleges and universities should allocate resources, construct work framework, plan work mode and design system and mechanism around the cultivation and application of intellectual property, and give full play to the role of intellectual property in enhancing innovation value [7].

(2) Strengthen organizational allocation. Constantly optimize the organizational design and corresponding responsibilities of science and technology management, and take intellectual property as the key consideration. The work of the school technology transfer center, local sub-centers and local research institutes all introduce intellectual property operation elements, 
closely linking technology transfer with intellectual property operation. The establishment of a patent cultivation and operation center with materialized operation will solve the inherent defects in the organization and management of intellectual property in colleges and universities through a market-oriented mechanism.

(3) Strengthen process management. Intellectual property management will be integrated into all aspects of scientific research projects, such as topic selection, project initiation, implementation, conclusion and achievement transformation. In the patent creation stage, relying on the professional team of the patent cultivation and operation center, the patent layout and mining mechanism are established, so that the scheme with market prospect can get reasonable patent protection in time; In the stage of patent application, multi-level patent quality management will be implemented, patent applications will be pre-examined, and the technological advancement and market prospect of inventions and creations will be evaluated. In the stage of patent transformation, in view of the large number of existing patents in colleges and universities, patent classification management is implemented, and a qualityoriented patent transformation pricing mechanism is implemented based on the classification results, so as to promote the school patent cultivation and operation center to carry out patent collection, storage and custody, and enhance the value of school scientific and technological achievements [8].

\subsection{Form a linkage mechanism among universities, enterprises and government}

Strengthen the communication among universities, enterprises and governments. To improve the practicability of intellectual property achievements in Colleges and universities and their conformity with local industries and trades. Local governments should play a functional role, improve the enthusiasm of enterprises in school-enterprise cooperation, and reduce the worries of enterprises and universities. Local governments should also improve the financial capital integration mechanism. Colleges and universities should improve the management and service mechanism of intellectual property. Scientific research management system led by science and technology department and coordinated by personnel and finance departments. Colleges and universities and the government should break through the system barriers, separate the intellectual property management departments of colleges and universities, gradually transform them into intermediary service institutions supported by the government, open up the transformation channels, and realize the synchronization and accuracy of transformation information.

\section{Acknowledgement}

This paper was sponsored by the University Patent Development Project of Intellectual Property Office of Heilongjiang province in 2019 (201905).

\section{Reference}

[1] H. Shi, X. Du, and H. Li, "Analysis on intellectual property management of agricultural universities based on achievement transformation orientation," Heilongjiang Animal Husbandry and Veterinary Medicine, vol.12, pp.49-52, (2018) DOI: 10.13881/j.cnki.hljxmsy.2017.08.0069

[2] P. Wang, "Research on the growth environment of small and medium-sized technological enterprises," M.S. thesis, College of Environmental Science and Engineering, Ocean University of China, Qingdao Tsingtao, China, (2006) 
[3] W. Yang, L. Zhou, "Research on countermeasures to promote decryption, transfer and transformation of national defense patents in China," China Economic and Trade Guide, vol.08, pp.59-62, (2018)

[4] S. Chen, "Research on rapid promotion of university patent creation ability-taking taizhou university as an example," Journal of Hubei Correspondence University, vol.30, no.19, pp.3-5, (2017)

[5] Z. Yang, H. Zhang, and H. Xu, "Research on the transformation of scientific and technological achievements in korean universities--taking "Industry-University-Research Cooperation Foundation" as an example," Science and Technology in Chinese Universities, vol.11, pp.11-14, (2012)

[6] S. Li, "Colleges and universities should strengthen social service function," Liaoning Education, vol.04, pp.31, (2012)

[7] W. Lu, R, P. Fan, and J. Wang, "Research on intellectual property policy of collaborative innovation in integration of defense and civilian," China Economic and Trade Guide, vol.14, pp.64-65, (2018)

[8] H. Jiang, "Research on the current situation and countermeasures of intellectual property work in colleges and universities," Jiangsu Higher Vocational Education, vol.19, no.01, pp.94-97, (2019) 